\title{
O PERFIL DOS TRANSPORTES AÉREOS NEONATAIS DE UMA EMPRESA PRIVADA EM BELO HORIZONTE, MINAS GERAIS
}

\author{
CARVALHO Vânia Paula1; SILVA Bruno Gonçalves²; AMARAL Rosana Costa3; \\ FERREIRA Flávio Lopes ${ }^{4}$
}

RESUMO: O transporte inter-hospitalar é realizado em aeronaves com infraestrutura de uma Unidade de Terapia Intensiva Neonatal (UTIN). Na presente pesquisa, o objetivo foi avaliar o perfil epidemiológico das aerorremoções interhospitalares neonatais e realizar algumas considerações sobre as especificidades deste tipo de transporte aéreo. Trata-se de uma pesquisa quantitativa, de caráter observacional, descritiva, realizada por uma empresa privada, situada em Belo Horizonte - MG, Brasil. A coleta de dados ocorreu entre janeiro de 2012 a dezembro de 2017. A amostra foi constituída de 699 recém-nascidos e os dados foram obtidos. através de banco de dados e da análise das fichas de voo. O estudo foi aprovado pelo Comitê de Ética e Pesquisa sob parecer no 09/2019. A incidência de voos neonatais teve a média de 21,98\% anual, faixa etária com mediana de 2 dias, maioria sexo masculino $55,13 \%$ e a maior incidência entre as categorias diagnósticas nas doenças do 'aparelho cardiovascular' (25,91\%). O trabalho realizado com equipe experiente, especializada e equipamentos de primeira geração otimizam as chances de sobrevida dos neonatos.

Descritores: Transporte de pacientes, Enfermeiro, Neonato

\section{INTRODUÇÃO}

O transporte inter-hospitalar é realizado em aeronaves com infraestrutura de Unidade de Terapia Intensiva (UTI) e atende a todas as faixas etárias. Abordaremos, em especial, o cenário do transporte aéreo do neonato (0 a 28 dias) e algumas de suas particularidades.

A melhor incubadora existente é o útero materno, contudo, por diversos motivos, nem sempre é possível o transporte da gestante em tempo hábil (MENDES, 1995; VIANA, 2008). A Portaria 2048, de Novembro de 2002, do Ministério da Saúde, regulamenta todos os tipos de transportes de pacientes. As ambulâncias (terrestres, aéreas ou aquaviárias) são definidas como veículos que se destinam exclusivamente a transporte de enfermos.

1.Enfermeira de Bordo e Coordenadora de Enfermagem (RT) da Unimed Aeromédica BH. Mestre e pesquisadora do Grupo de Pesquisas SAUVI Trânsito. Docente da Faculdade de Ciências Médicas de Minas Gerais e Docente convidada do IEC- PUCMG. E-mail: vaniapaula.carvalho@gmail.com

2. Enfermeiro de bordo da Unimed Aeromédica. Doutorando Tecnologia da Informação e Gestão do Conhecimento, pela FUMEC - BH. Docente da Faculdade de Ciências Médicas de Minas Gerais. Especialista em Terapia Intensiva, pediátrica, neonatal e adulto. E-mail: brunoenf87@gmail.com

3. Enfermeira de bordo da Unimed Aeromédica; Mestre e Coordenadora Pedagógica Realística e Habilidades da Faculdade de Ciências Médicas de Minas Gerais. E-mail: rosana.vass@gmail.com

4. Gestor médico da Unimed Aeromédica, Mestre e Doutorando em Ciências Biológicas com Área de Concentração em Farmacologia e fisiologia, Docente da Faculdade de Ciências Médicas de Minas Gerais. E-mail: flopes@unimedaeromedica.com.br 
Segundo a Portaria, a ambulância classificada como Tipo E é destinada ao transporte aeromédico, dividindo-se em: asa fixa (aviões) ou asa rotativa (helicópteros) e são utilizadas no transporte inter-hospitalar de pacientes e em ações de resgate.

Essas aeronaves são dotadas de equipamentos médicos homologados pelo Departamento de Aviação Civil, atualmente pela Agência Nacional de Aviação Civil ANAC (PEGADO, 2010). Com a evolução dos equipamentos e com a utilização de tecnologia de ponta, a efetivação do transporte fica cada vez mais segura. Claro que a 'máquina' humana é soberana e, sem dúvidas, o trabalho em equipe é primordial para que o transporte transcorra com segurança e eficácia.

\section{OBJETIVOS}

Analisar o perfil dos transportes aeromédicos inter-hospitalares, de pacientes em faixa etária neonatal, realizados por um serviço terceirizado.

\section{METODOLOGIAS}

Trata-se de uma pesquisa quantitativa, de caráter observacional e descritivo. Foram analisadas 699 fichas (em total) de voos neonatais, realizados entre janeiro de 2012 a dezembro de 2017.

Foram respeitados os aspectos éticos, obedecidas as normas e diretrizes regulamentadoras definidas na Resolução n 466/12 do Conselho Nacional de Saúde - Ministério da Saúde. O projeto foi submetido à apreciação do Comitê de Ética em Pesquisa da Unimed Aeromédica sendo aprovado Conforme o Parecer № 09/2016.

\section{DISCUSSÕES}

Habitualmente, logo após a confirmação da vaga no hospital de destino, é disparado o acionamento da equipe aeromédica para missão. Além disso, há necessidade de materiais específicos para a realização adequada do transporte neonatal.

Dos materiais e equipamentos necessários para realização do transporte aeromédico, estão inclusos: a incubadora de uso obrigatório para transporte neonatal, com bateria e base especial para transporte aéreo, suporte em sua base 
para cilindros de oxigênio e ar comprimido (com chicotes que permitem abertura e fechamento do oxigênio sem desconexão e fluxômetro, dupla via para oxigênio, umidificador, dentre outros), controle de temperatura com alarme, base especial para fixação na aeronave e na ambulância; suporte para fixação dos equipamentos; foco de luz, conversor de eletricidade e cabo de força (para conectar o equipamento durante o transporte) e vários outros materiais e equipamentos específicos.

A equipe deve repassar para os colegas da UTIN um relatório completo de todos os procedimentos, parâmetros, enfim, condutas tomadas durante o transporte e da evolução da criança até o hospital de destino. Além de todos esses cuidados prestados ao neonato, faz-se necessário atentar-nos para as particularidades do transporte aeromédico, tais como: (1) Em caso de acidentes, as fixações devem ser suficientes para evitar danos secundários aos pacientes e à tripulação; (2) Devemos contar com uma equipe multiprofissional altamente especializada, com treinamento, experiência e que domine os equipamentos altamente técnicos; (3) No caso de pacientes em ventilação mecânica, é importante verificar se o ventilador é capaz de monitorizar a pressão ambiente e realizar as compensações adequadas em decorrência das alterações na densidade e na viscosidade dos gases. No caso de ciclagem a volume, é importante observar essa correção, visto que o volume corrente irá ser menor em aparelhos que não possuem a correção automática. No caso de ciclagem a pressão, esses efeitos são menos observados, mas, devido à menor pressão parcial do gás inspirado, eles podem afetar o volume corrente e o volume minuto. Para evitar problemas, a monitorização desses parâmetros deve ser realizada e é essencial que a equipe tenha conhecimento prévio das características de seu equipamento antes do início da missão (UNIMED AEROMÉDICA, 2016). É necessário lembrar que as leituras de $\mathrm{ETCO}^{2}$ não sofrem variações com altitude; (4) A utilização de equipos com detectores de bolhas em sistemas de infusão é essencial (cata-bolhas); (5) O ruído é um problema para o neonato, especialmente nas aeronaves e particularmente em helicópteros. Ele traz danos à saúde do neonato e da tripulação, além de interferir na comunicação; (6) A falta de luminosidade adequada durante os voos noturnos dificulta bastante 0 atendimento ao paciente. Por outro lado, a luz solar excessiva prejudica a leitura do visor dos monitores em diversos ângulos (Mc GUIRE, 2006); (7) Devido à complementação terrestre, comum nos transportes aeromédicos, pois é assim que se realiza a 
remoção dos neonatos para os hospitais, devemos nos atentar para a velocidade do transporte da ambulância e a qualidade da via de acesso, pois há risco de sangramento intracraniano; (8) A incubadora, adaptada para aeromédico, com todos os equipamentos, pesa aproximadamente $150 \mathrm{~kg}$. É necessário que a tripulação, a equipe médica e da ambulância tenham uma excelente sintonia e trabalhem em equipe para otimizar uma assistência adequada e evitar eventos adversos; (9) Devem ser realizadas manutenções preventivas em todos os equipamentos, conforme recomendações pelo fabricante; (10) $O$ trabalho da equipe médica deve ser harmônico, realizado por profissionais altamente experientes, pois isso permite maior confiança, tranquilidade, reduz o estresse e os riscos para o neonato.

\section{RESULTADOS}

Com relação ao perfil epidemiológico do neonato aerorremovido observa-se que quanto à faixa etária (com a idade em dias) a média é de 5 , a mediana de 2 e 0 desvio médio de 4,8. Quanto ao sexo dos neonatos, $55,13 \%$ são do sexo masculino, $42,14 \%$ do feminino e $2,73 \%$ desconhecidos. A categoria diagnóstica de maior incidência foi a do 'aparelho cardiovascular' (25,91\%), seguidas de 'doenças neurológicas' (14,43\%) e 'trauma' (14,27\%).

\section{CONCLUSÕES}

Concluímos que a média anual de voos neonatais realizados foi de $21,98 \%$. A maioria dos transportados foi do sexo masculino, com idade média de 05 dias e se encontravam nas categorias diagnósticas com acometimento do aparelho cardiovascular, neurológicas e trauma.

Fazendo uma alusão à citação do saudoso Ratton (2005) "O cuidado intensivo baseia-se em um tripé: paciente grave, equipamento altamente técnico e equipe multiprofissional especializada, com conhecimentos e experiência para cuidar e tratar do paciente e manipular a aparelhagem".

\section{REFERÊNCIAS}

GUIRE Mc. Monitoring in the field. Br J Anesthesia. 2006; 97:46-56.

MENDES Cândida, et al. A. Transporte do RN para a UCIN terciária. SPN [base de dados na internet]. Lisboa; 1995 [Acesso em 2019 ago. 10]. Disponível em: < http://www.lusoneonatologia.net/page/publications/consensus/pt 
PEGADO Hélio de Assis. Monitoramento de Vibrações: uma ferramenta eficiente na prevenção de acidentes com helicópteros. Rev. Conexão SIPAER. 2010;1(1)

Procedimentos Operacionais Padrão. Unimed Aeromédica. Transporte Médico de Urgência. No prelo 2016.

RATTON José Amorim. Medicina Intensiva. 2aㅡ ed. Rio de Janeiro: Atheneu; 2005.

VIANA Dirce Laplaca, et al. Manual de Procedimentos em Pediatria. São Paulo: Yendis Editora; 2008. 